\title{
Temperature Dependence of the Microstructure and Mechanical Properties of a Twinning-Induced Plasticity Steel
}

\author{
Flavio De Barbieri ${ }^{1}$, Felipe Castro Cerda ${ }^{2}{ }^{(D)}$, Juan Pérez-Ipiña ${ }^{3}$, Alfredo Artigas ${ }^{2}$ and \\ Alberto Monsalve 2,* (iD) \\ 1 Departamento de Ingeniería Metalúrgica y de Materiales, Universidad Técnica Federico Santa María, \\ Valparaíso 2340000, Chile; flavio.debarbieri@usm.cl \\ 2 Departamento de Ingeniería Metalúrgica, Universidad de Santiago de Chile, Santiago 9160000, Chile; \\ felipe.castro@usach.cl (F.C.C.); alfredo.artigas@usach.cl (A.A.) \\ 3 Grupo Mecánica de Fractura, UNComa-CONICET, Neuquén 8300, Argentina; \\ juan.perezipina@fain.uncoma.edu.ar \\ * Correspondence: alberto.monsalve@usach.cl; Tel.: +56-2-2718-3214
}

Received: 26 January 2018; Accepted: 29 March 2018; Published: 12 April 2018

\begin{abstract}
The objective of the present study is to analyze the microstructure and mechanical properties of a twinning-induced plasticity (TWIP) steel at different temperatures. For this purpose, tensile tests were performed on a Fe-22Mn-0.65C TWIP steel in a temperature range between $25^{\circ} \mathrm{C}$ and $400{ }^{\circ} \mathrm{C}$. The microstructure after deformation was characterized via optical microscopy. It was observed that the microstructure consists of mainly deformation twins at low temperatures, whereas dislocation bands are the predominating feature at high temperatures. The analysis of mechanical data suggests a transition of the deformation mechanism from twinning at low temperatures to dislocation slip at high temperatures. The work-hardening rate and area reduction variation with temperature are discussed and correlated to the decrease of twinning contribution to the deformation mechanism. The role of other processes, such as dynamic strain aging and precipitation hardening, are discussed. A thermodynamic-based description for the dependence of yield stress with temperature was developed, suggesting two acting work-hardening mechanisms.
\end{abstract}

Keywords: twinning; TWIP steel; stacking fault energy; mechanical properties; work hardening

\section{Introduction}

Twinning-induced plasticity (TWIP) steels are high-Mn austenitic steels belonging to the second generation advanced high-strength steels (AHSS) which exhibit a high work hardening and elongation to fracture [1]. Their main characteristics have been discussed in detail elsewhere [2-4]. The so-called TWIP steels have gained considerable attention from the automotive industry due to their excellent impact properties [3], which are desirable for improving passenger safety performance and environmental standards.

The mechanisms leading to the outstanding work hardening of TWIP steels are still a matter of discussion [4]. Twinning generates a very fine microstructure that restricts dislocation glide, favoring deformation hardening and making energy absorption a very efficient mechanism [3]. The contribution of twinning to the deformation process depends not only on the extent and frequency, but also on the strain level associated with the twin formation [5]. So far, a general temperature and strain-rate dependences of deformation mechanisms in polycrystalline aggregates have been established $[5,6]$. Even though at all temperatures, perfect slip is active, at low temperatures, perfect and partial slip occur together with twinning; at high temperatures, perfect slip occurs. Analogous behavior is noticed 
at high and low strain rates. Jung and De Cooman [7] studied the tensile properties of Fe-18Mn-0.6C (weight percent) with additions of $\mathrm{Al}$ in the temperature range $-60^{\circ} \mathrm{C}$ to $140{ }^{\circ} \mathrm{C}$. They observed a steady decrease in both the yield stress and the work hardening as the temperature increases, which was attributed to the thermally activated dislocation glide. The decrease in work hardening with increasing temperature was explained by the suppression of twin formation due to the increase in the stacking fault energy.

The mechanical behavior of low stacking fault energy (SFE) steels is a rather complex process in which twinning is among other dislocation-related interactions [8,9]. At very low SFE values $\left(<18 \mathrm{~mJ} / \mathrm{m}^{2}\right)$, the deformation mode includes the $\gamma \rightarrow \varepsilon$ and $/$ or $\gamma \rightarrow \alpha$ martensitic transformations (where $\gamma$ corresponds to austenite, $\varepsilon$ and $\alpha$ correspond to martensite), leading to transformation-induced plasticity (TRIP) phenomena; while at values between 20 and $45 \mathrm{~mJ} / \mathrm{m}^{2}$, twinning is favored, and plasticity enhanced. Above these stacking fault energy values, dislocation glide is the predominating deformation mode $[4,10]$. It is known that SFE depends on chemical composition and temperature. If the temperature is increased, the SFE increases, decreasing the possibility of generating mechanical twinning during plastic deformation [4]. During the last few years, continuous efforts have been made in order to understand the micromechanics of twinning. Rahman et al. [11], by means of synchrotron X-ray diffraction, found that twinning can occur before macroscopic yielding. Nevertheless, Saleh and Gazder [12] have recently published a re-evaluation of the Rahman paper, proving their idea wrong and providing a further discussion for the initiation of deformation twinning. Galindo-Nava and Rivera Díaz [13] studied the evolution of martensite and twinning in austenitic steels, finding that the critical size for twin formation is obtained by minimizing the free energy of formation. Wong et al. [14] have developed a dislocation density-based crystal plasticity model incorporating both transformation-induced plasticity (TRIP) and twinning-induced plasticity (TWIP), validating the model in a Fe-22Mn-0.6C steel and then predicting the deformation mechanisms at different temperatures.

The goal of the present research is to study the temperature variation of the mechanical properties of a Fe-22Mn-0.65C TWIP steel at temperatures between $25^{\circ} \mathrm{C}$ and $400{ }^{\circ} \mathrm{C}$, with emphasis in the 300 to $400{ }^{\circ} \mathrm{C}$ interval. Tensile tests allowed the measurement of yield stress $\left(\sigma_{\mathrm{ys}}\right)$, ultimate tensile strength (UTS), elongation to fracture $(\delta \%)$, area reduction $(\phi \%)$, and the strain hardening exponent $(n)$. Metallographic observations are correlated with the work-hardening mechanism, stacking fault energy SFE, and an activation energy-based model. The results showed a transition in the work-hardening mechanism from twinning to dislocation glide around $325^{\circ} \mathrm{C}$. The contribution of other processes, such as dynamic strain aging and precipitation hardening, is analyzed.

\section{Materials and Methods}

A TWIP steel was melted in an induction furnace, casting a $100 \times 100 \times 300 \mathrm{~mm}^{3}$ ingot. The ingot was forged at $1200{ }^{\circ} \mathrm{C}$ to a $23 \times 110 \times 1070 \mathrm{~mm}^{3}$ sheet. Internal quality of the forged plate was verified through ultrasound inspection before cutting smaller plates of $23 \times 110 \times 20 \mathrm{~mm}^{3}$ that were homogenized at $1100{ }^{\circ} \mathrm{C}$ during $40 \mathrm{~min}$, before rolling down to $12 \mathrm{~mm}$ thickness. The rolled steel was quenched in a salt-bath at $350^{\circ} \mathrm{C}$, held at that temperature for $30 \mathrm{~min}$, and subsequently cooled to room temperature.

Standard tensile test specimens were machined according to ASTM E8 standard (120 mm long and $6 \mathrm{~mm}$ diameter), the length being parallel to the rolling direction. Tensile testing was carried out in a Tinius-Olsen 2000 Super L $300 \mathrm{kN}$ capacity machine (Horsham, PA, USA) at a speed of $2.5 \mathrm{~mm} / \mathrm{min}$, testing three specimens at each temperature: room $\left(25^{\circ} \mathrm{C}\right), 100,200,300,325,350,375$, and $400{ }^{\circ} \mathrm{C}$, with the aid of a special furnace. The data acquisition rate was 64 points/s. Each test produced around 65,000 points. In accordance with previous experiments, this data acquisition rate is high enough to detect dynamic strain ageing (DSA) effect. As the use of displacement transducers at high-temperature testing was not feasible, the elongation was measured as the crosshead displacement, and the strain was characterized by this displacement divided by the initial length of the reduced section of each specimen. 
Metallographic characterization was carried out according to the standard grinding and polishing procedures. The as-polished surface was etched with Vilella's reagent $(100 \mathrm{~mL}$ ethanol, $5 \mathrm{~mL}$ $\mathrm{HCl} 37 \% v / v$, and $1 \mathrm{~g}$ of picric acid). The microstructure was observed in an Olympus optical microscope (Tokyo, Japan). Each tensile sample was observed in the homogeneous deformation zone. Determination of grain size was performed according to the ASTM E112 standard.

X-ray measurements were carried out in a Shimadzu LabX XRD 6000 diffractometer (Kyoto, Japan), equipment Copper $\mathrm{K} \alpha$ source. The measurements were run from $20^{\circ}$ to $120^{\circ}$ at $0.02^{\circ}$ step size and a rate of $2^{\circ} / \mathrm{min}$.

Room-temperature SFE was computed from an X-ray diffraction pattern with the aid of the MAUD (materials analysis using diffraction) license-free software [15].

Stacking fault energy was also calculated through a thermodynamic model $[16,17]$ for the studied temperatures. The thermodynamic model is based on the proposals of Olson and Cohen [18], who suggested that SFE $\left(\mathrm{J} / \mathrm{m}^{2}\right)$ can be computed from the free energy of the transformation $\gamma \rightarrow \varepsilon$, Equation (1).

$$
\mathrm{SFE}=2 \rho_{\mathrm{A}} \cdot \Delta \mathrm{G}^{\gamma \rightarrow \varepsilon}+2 \sigma^{\frac{\gamma}{\varepsilon}}
$$

where $\Delta \mathrm{G}^{\gamma \rightarrow \varepsilon}(\mathrm{J} / \mathrm{mol})$ is a function of the chemical composition of the steel and the absolute temperature; $\rho_{\mathrm{A}}$ is the atomic density of the (111) plane $\left(\mathrm{mol} / \mathrm{m}^{2}\right)$, and $\sigma^{\frac{\gamma}{\varepsilon}}\left(\mathrm{J} / \mathrm{m}^{2}\right)$ is the interfacial energy between $\gamma$ and $\varepsilon$ phases. The values used in this work were obtained from Curtze et al. [19].

\section{Results}

\subsection{Initial Material}

The chemical composition of the steel is shown in Table 1. Figure 1a shows the initial microstructure before tensile test, consisting of equiaxed austenitic grains. Annealing twins can also be observed. Cementite was not observed, and it is corroborated via X-ray measurements (Figure 1b) due to the absence of peaks corresponding to cementite.

Table 1. Chemical composition of the twinning-induced plasticity (TWIP) steel (weight \%).

\begin{tabular}{cccccc}
\hline $\mathbf{C}$ & $\mathbf{M n}$ & $\mathbf{S i}$ & $\mathbf{C r}$ & $\mathbf{P}$ & $\mathbf{S}$ \\
\hline 0.65 & 22.14 & 0.16 & 0.28 & 0.060 & 0.007 \\
\hline
\end{tabular}

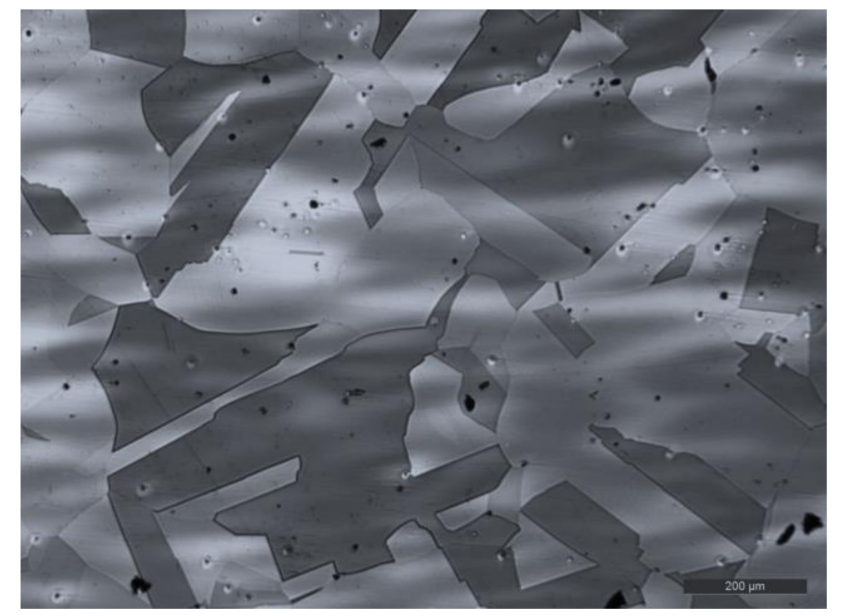

(a)

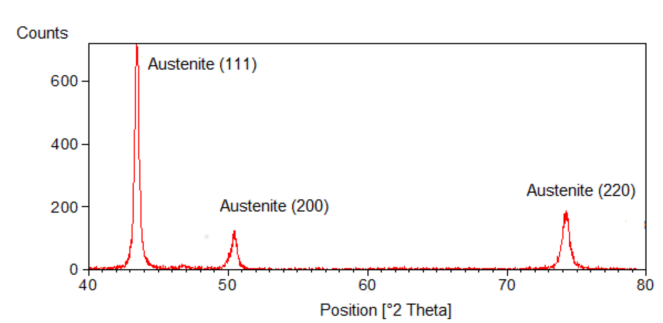

(b)

Figure 1. (a) Optical metallography (scale bar $200 \mu \mathrm{m}$ ) and (b) XRD pattern of the material before tensile tests; etched with Vilella's reagent. 


\subsection{Microstructure after Tensile Tests}

Figure 2 corresponds to the microstructures of samples at $25,325,350$, and $375{ }^{\circ} \mathrm{C}$, respectively (300 and $400{ }^{\circ} \mathrm{C}$ were not included because of their similitudes with 325 and $375{ }^{\circ} \mathrm{C}$, respectively). A clear change in the response of the etching to the microstructure is noticed as the testing temperature is increased. At $25^{\circ} \mathrm{C}$ (Figure 2a), it is observed that mechanical twinning is the predominating feature in the microstructure. Twins are also observed at $325^{\circ} \mathrm{C}$ (Figure $2 \mathrm{~b}$ ), yet it becomes less frequent in the microstructure at $350{ }^{\circ} \mathrm{C}$ (Figure 2c). At $375^{\circ} \mathrm{C}$, twins are only observed in some scattered grains, while dislocation bands (black arrow in Figure $2 \mathrm{~d}$ ) are revealed.
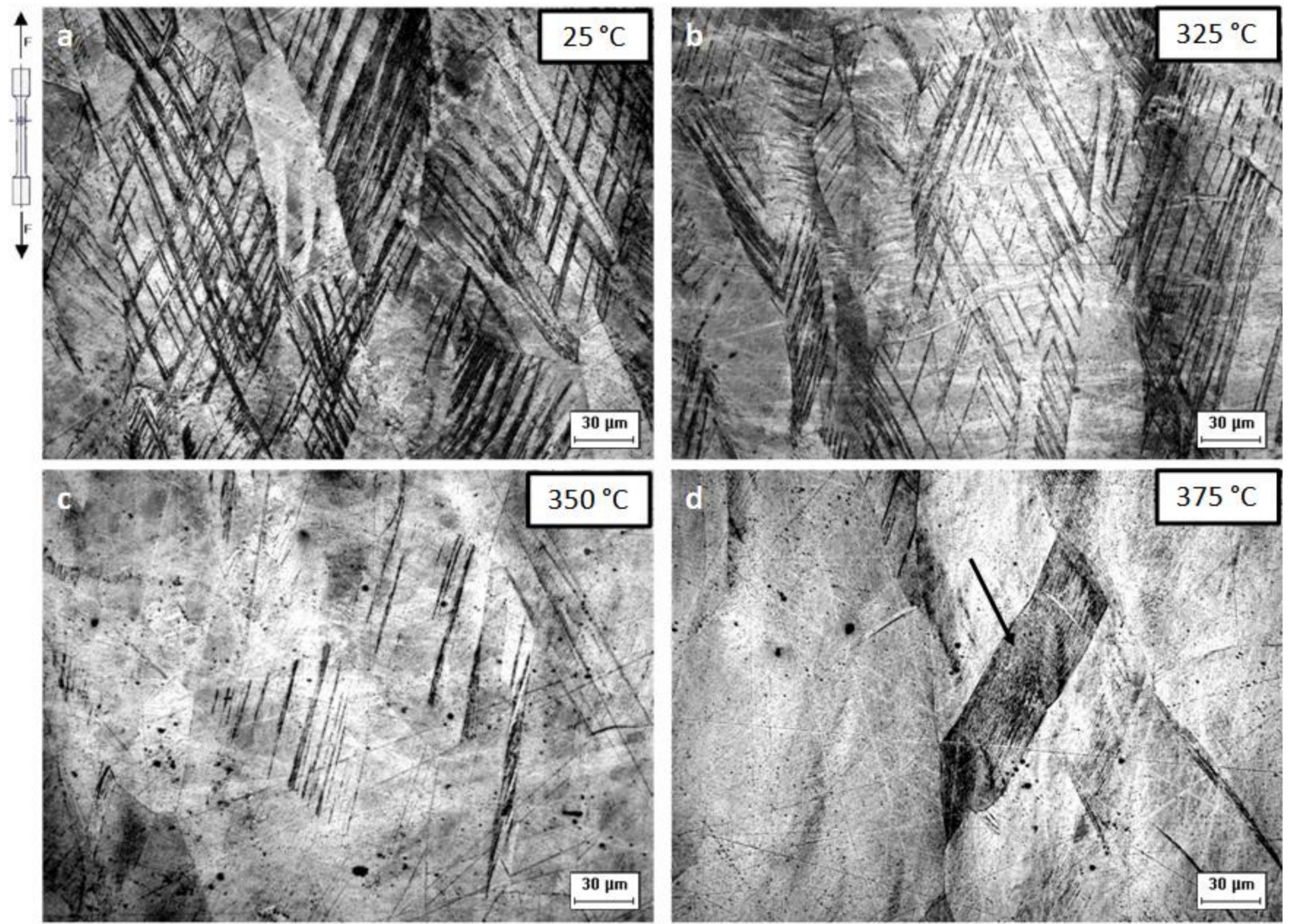

Figure 2. Microstructure of samples after tensile tests at (a) $25^{\circ} \mathrm{C}$, (b) $325^{\circ} \mathrm{C}$, (c) $350{ }^{\circ} \mathrm{C}$, and (d) $375{ }^{\circ} \mathrm{C}$; etched with Vilella's reagent. $\mathrm{F}$ is the applied force.

\subsection{SFE Calculations}

Figure 3 shows the calculated stacking fault energy as described in Section 2. Both SFE values at $25^{\circ} \mathrm{C}$, calculated from the model by Olson and Cohen and with MAUD, are in reasonable agreement. They are within the theoretical range of twinning deformation [10].

\subsection{Tensile Tests}

Representative stress-strain curves obtained from the tensile tests are presented in Figure 4; Table 2 shows the corresponding results. It is noticed that as the temperature increases, the yield stress $\left(\sigma_{\mathrm{ys}}\right)$ and ultimate tensile strength (UTS) generally decrease. The elongation at fracture and area reduction show high values in practically all cases and increased with temperature. 


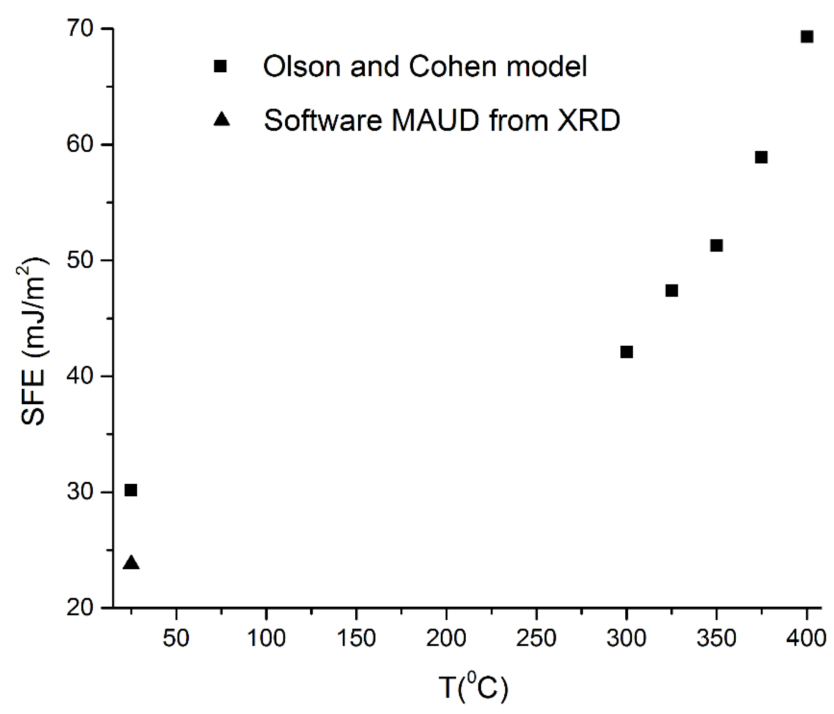

Figure 3. Stacking fault energy (SFE) vs temperature ( $T$ ).

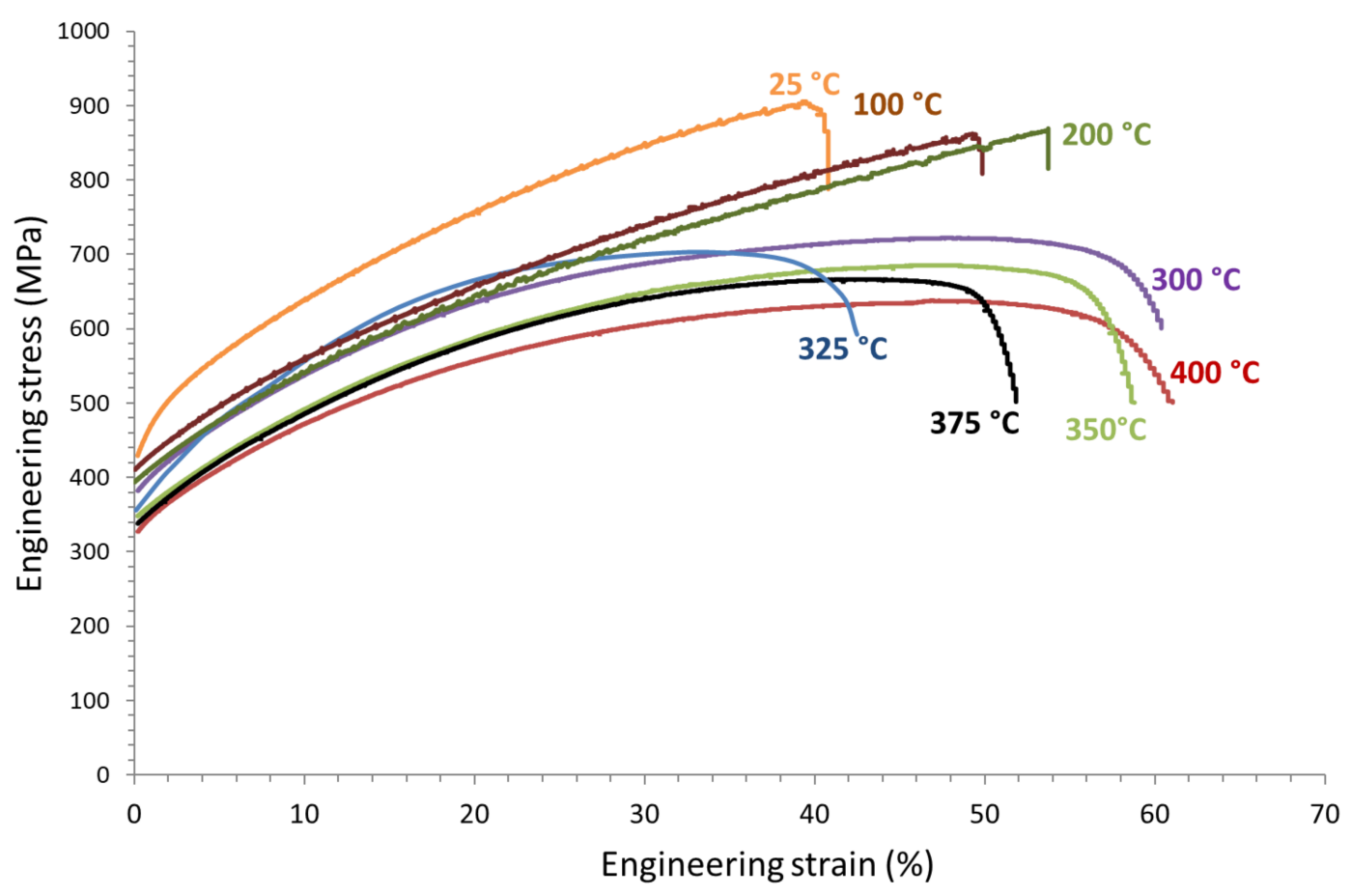

Figure 4. Stress-strain curves of tensile tests at different temperatures [20].

Table 2. Results of tensile testing at different temperatures. UTS: ultimate tensile strength.

\begin{tabular}{cccccc}
\hline Temperature $\left({ }^{\circ} \mathbf{C}\right)$ & $\boldsymbol{\sigma}_{\text {ys }}(\mathbf{M P a})$ & UTS $(\mathbf{M P a})$ & $\boldsymbol{\delta} \%$ & $\boldsymbol{\phi} \%$ & $\boldsymbol{n}$ \\
\hline 25 & $429 \pm 8.6$ & $905 \pm 0.7$ & 40.8 & 40.2 & 0.47 \\
100 & $415 \pm 2.5$ & $841 \pm 1.5$ & 50.01 & 46.22 & 0.44 \\
200 & $403 \pm 12.2$ & $842 \pm 3.3$ & 53.8 & 52.1 & 0.43 \\
300 & $382 \pm 24$ & $722 \pm 4.9$ & $60.4 \pm 0.9$ & $60.2 \pm 9.3$ & 0.42 \\
325 & $356 \pm 4.6$ & $701 \pm 9.8$ & $42.6 \pm 1.7$ & $64.8 \pm 3.3$ & 0.40 \\
350 & $348 \pm 9.4$ & $688 \pm 30.7$ & $58.8 \pm 1.8$ & $77.4 \pm 1.7$ & 0.34 \\
375 & $338 \pm 4.0$ & $664 \pm 0.7$ & $51.8 \pm 4.0$ & $84.0 \pm 0.5$ & 0.32 \\
400 & $327 \pm 5.0$ & $638 \pm 2.1$ & $61.0 \pm 1.6$ & $80.4 \pm 1.5$ & 0.26 \\
\hline
\end{tabular}


Discontinuous serrated curves were measured at $25^{\circ} \mathrm{C}, 100{ }^{\circ} \mathrm{C}$, and $200{ }^{\circ} \mathrm{C}$ (cf. Figure 5). Previous studies [21] have related the serrations to the presence of dynamic strain aging, also known as the Portevin-Le Chatelier effect. Serrations were not observed above $300^{\circ} \mathrm{C}$. Necking was only noticeable in samples tested at temperatures above $325^{\circ} \mathrm{C}$, as can be seen in Figure 6. Below $325^{\circ} \mathrm{C}$, localized strain was not significant (cf. Table 2).

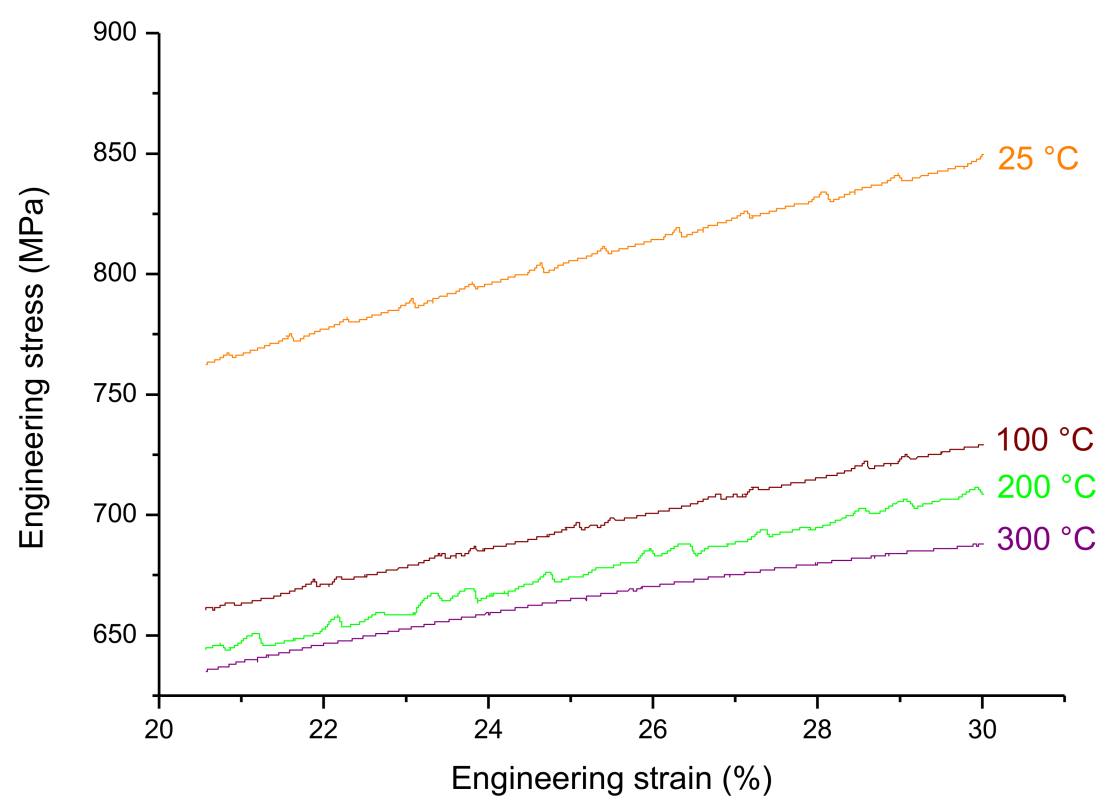

Figure 5. Stress-strain curves of tensile tests at different temperatures between $20 \%$ and $30 \%$ engineering strain.

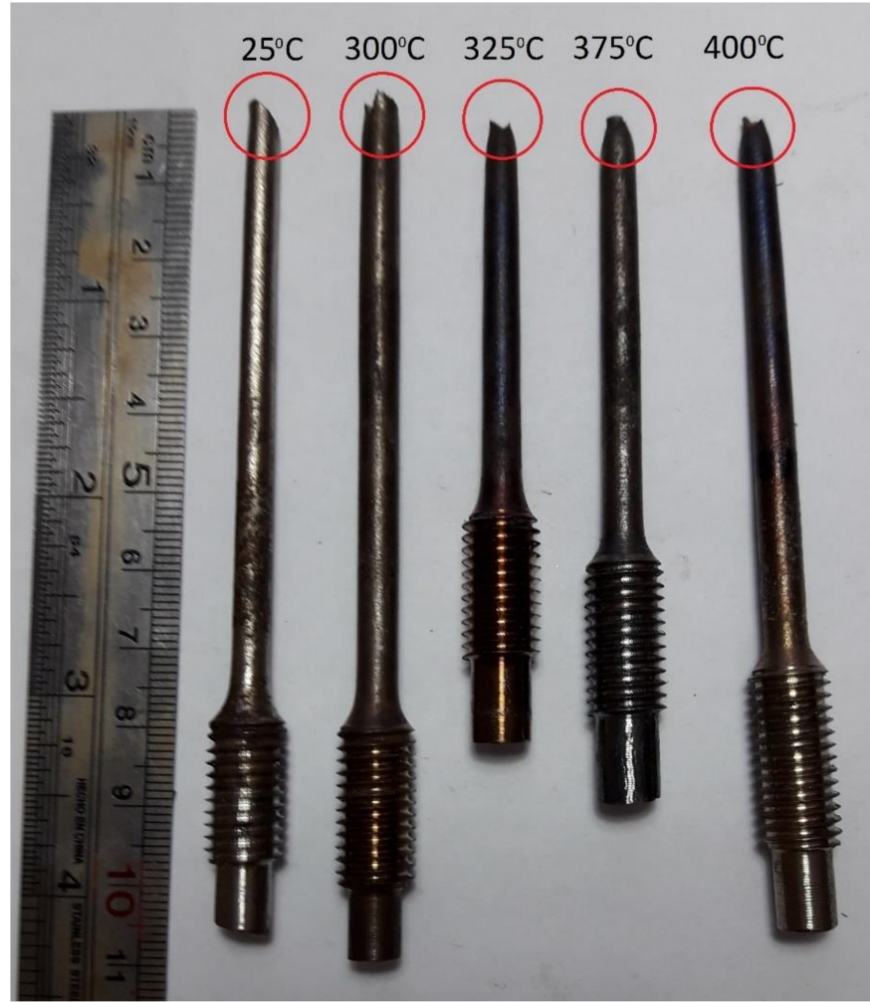

Figure 6. Tensile specimens at different temperatures. Red circles indicate the fractured zone. 
Figure 7 shows the temperature dependence of strain hardening (Figure 7a) and area reduction (Figure $7 \mathrm{~b}$ ). Strain hardening index decreases and area reduction increases as temperature increases.

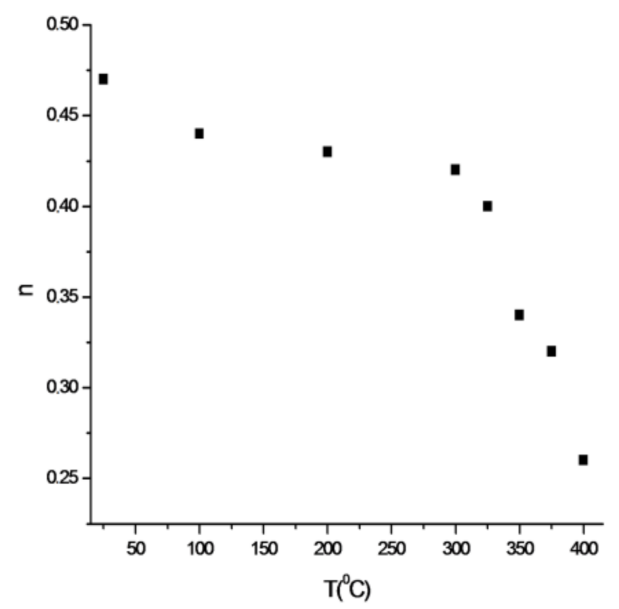

(a)

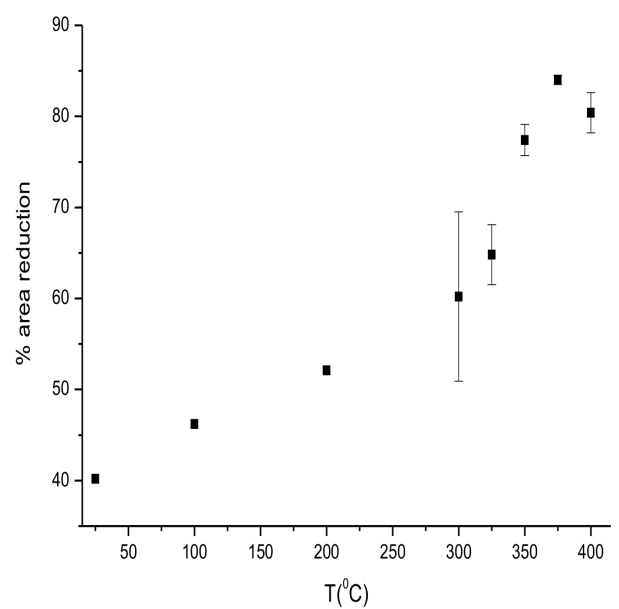

(b)

Figure 7. Variation of mechanical properties with temperature: (a) strain hardening and (b) reduction of area at failure.

\section{Discussion}

\subsection{Microstructure Evolution after High-Temperature Tensile Tests}

Metallographic observation (Figure 2) indicates a microscopic transition in the deformation mode. At temperatures up to $325{ }^{\circ} \mathrm{C}$, the predominating microstructural feature is mechanical twinning, whereas above $325^{\circ} \mathrm{C}$, dislocation bands are observed. The arrow in Figure $2 \mathrm{~d}$ shows a dislocation band revealed in what seems to be an annealing twin, which suggests that dislocation slip is the predominating mechanism at $375^{\circ} \mathrm{C}$. Although carbides were not detected via optical metallography, the possibility of precipitation hardening cannot be ruled out. This point will be further discussed in Section 4.2.2. Interrupted experiments carried out at different temperatures also show twinning in the same temperature range. This implies that at temperatures lower than $325^{\circ} \mathrm{C}$, twinning appears from the first stages of the tensile test.

As stated in the introduction, SFE values above $\sim 45 \mathrm{~mJ} / \mathrm{m}^{2}$ predict a deformation mode consisting mainly of dislocation slip. Figure 3 displays the calculation of SFE, whose calculated values above $325{ }^{\circ} \mathrm{C}$ fall well above the suggested limit for a dislocation-controlled deformation mechanism. Despite the high calculated stacking fault energy above $300^{\circ} \mathrm{C}$, metallographic observation (Figure 2b) shows that twinning is still an active mechanism at $325^{\circ} \mathrm{C}$. Combined metallographic analysis and thermodynamic calculations thus suggest that the temperature dependence of the deformation mode in the studied material displays a rather continuous transition, instead of a sharp limit.

\subsection{Tensile Tests Analysis}

\subsubsection{Effect of Temperature on Strength}

The temperature dependence of the yield stress [21] can be expressed according to Equation (2):

$$
\sigma=C \exp \left(\frac{Q}{R T}\right)
$$

where $Q$ is the activation energy for deformation $(\mathrm{J} / \mathrm{mol}), R$ is the ideal gas constant $(8.314 \mathrm{~J} / \mathrm{mol} \mathrm{K})$, $\sigma$ is the stress at temperature $T$, and $C$ is a constant that depends on the material. Figure 8 shows 
the logarithm of yield stress versus $1 / T$. The slope of the plot can be related to the activation energy. Two straight lines can be fitted at low and high temperatures, respectively, suggesting the existence of two different activation energies, and therefore, deformation mechanisms. Although the number of experimental points is limited and agreement with the experimental evidences is fair $\left(30{ }^{\circ} \mathrm{C}\right.$ vs. $\left.325^{\circ} \mathrm{C}\right)$, the general shape of the curve suggests a smooth transition of activation energy for the yield stress as the temperature is raised. The calculated $Q$ at low temperature is $\sim 0.6 \mathrm{~kJ} / \mathrm{mol}(\sim 0.006 \mathrm{eV} /$ atom $)$, whereas at high temperatures $Q \approx 4 \mathrm{~kJ} / \mathrm{mol}(\sim 0.04 \mathrm{eV} /$ atom). The value of low temperature $Q$ is in excellent agreement with that calculated by Christian and Mahajan [6] for the nucleation of twins. High-temperature $Q$ values are well below the reported activation energies for dynamic strain aging (DSA, $0.86 \mathrm{eV} /$ atom [4]) thus, suggesting that the active deformation mechanism at high temperatures is dislocation slip. The results of the present study are in concordance with the findings of Jung and De Cooman [7], regarding the transition in deformation mechanisms with temperature.

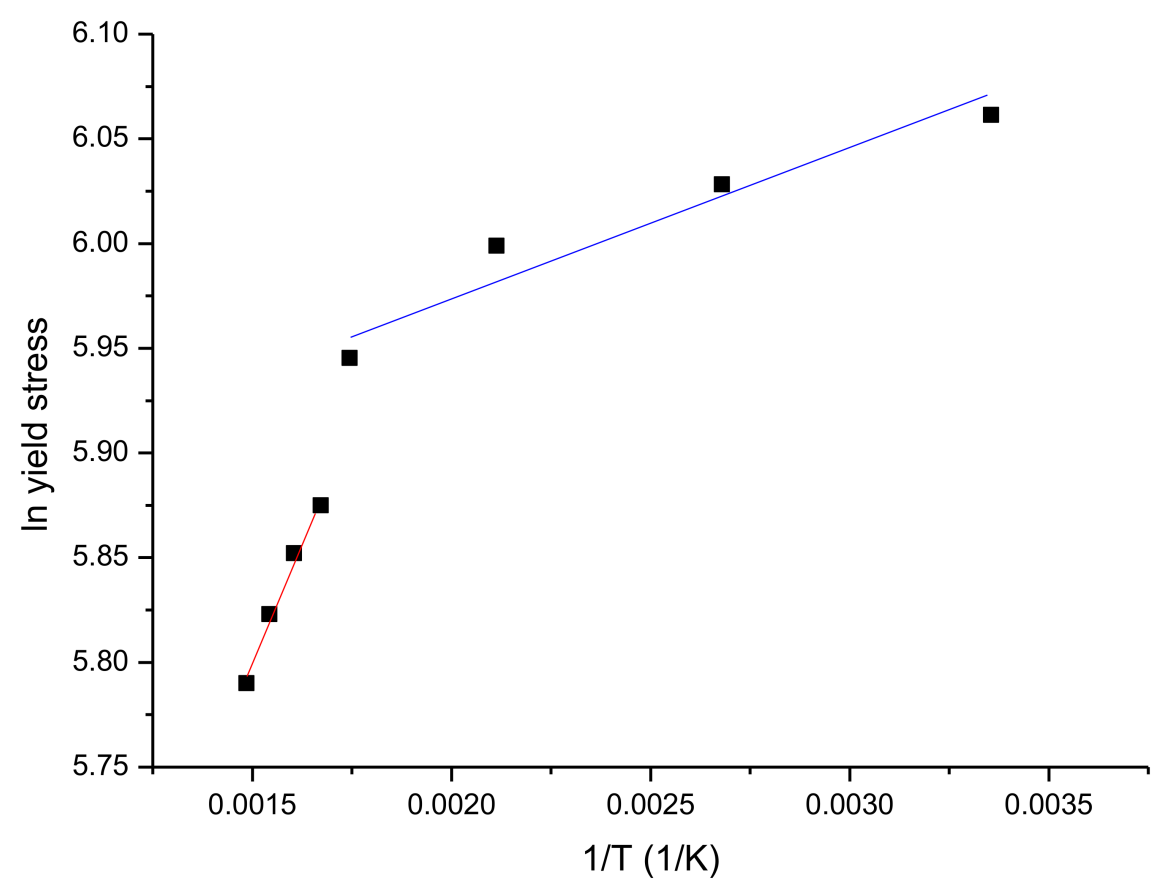

Figure 8. Plot of yield stress vs. 1/T.

\subsubsection{Effect of Temperature on Hardening Behavior}

Table 2 shows that the $n$-values decrease as the temperature is raised. The elevated work hardening of twinning-assisted steels has been rationalized elsewhere [3] as a consequence of the grain refining effect, which serves as an effective barrier to dislocation movement. This is consistent with the metallographic observation (cf. Figure 2a,b) of samples at low temperatures. Since twinning is reduced as the temperature is raised, the work-hardening effect is also less intense. As discussed in the previous sections, the calculated activation energies suggest that DSA does not play a significant role in the variation of yield stress with temperature, yet it is a significant factor as the stress approaches the UTS at $25{ }^{\circ} \mathrm{C}$ (cf. Figure 4). Therefore, DSA is believed to play a significant role in the work hardening of the studied steel, although the determination of its quantitative impact is beyond the scope of the present work.

\subsubsection{Other Structure-Property Relations}

The noticeable impact of temperature on the localization of strain is shown in Figures 6 and $7 \mathrm{~b}$. Such variation can be interpreted as a consequence of the change in deformation mechanism. At low temperatures, the strain is mainly accommodated by twinning, whereas the necking at high temperatures 
is related to the dislocation slip. However, it must be kept in mind that triaxiality in strain after UTS could induce other deformation mechanisms, so the area reduction itself and/or total elongation after fracture could not be explained only by a competition between twinning and dislocation glide. Nevertheless, the delay in the necking appearance generates a very small range of heterogeneous plastic deformation, (see Figure 4), and then it is expected that the total elongation of the samples could be related to twinning or dislocation glide, as a first approach. The marked decrease in UTS with temperature (cf. Table 2) might as well be influenced by the localization of strain. Other factors potentially affecting the mechanical behavior of TWIP steels, such as cementite precipitation and martensitic transformation, were not detected under the conditions of the present experiments.

For a better understanding of the mechanical properties of the steel, the strain hardening $\frac{d \sigma_{v}}{d \varepsilon_{v}}$ against $\varepsilon_{v}$ has been plotted in Figure 9. As can be seen, the upper curve corresponds to the tensile test carried out at $25^{\circ} \mathrm{C}$ and the lower curve represent experiments made at $350{ }^{\circ} \mathrm{C}$. This means that the maximum strain hardening occurs at room temperature, which is in accordance with the maximum difference between UTS and yield strength for this temperature (see Table 2). The meaning of this is that the twinning could be more effective in the strain hardening than dislocation glide. Metallographic analysis corroborates the twinning mechanism for low temperatures and the dislocation glide at $T>325^{\circ} \mathrm{C}$. Also, from Figure 9, in all cases, the maximum value for the derivative is related to the first stage of the tensile test, low strain, which is consistent with the fact that the material has a higher hardening capacity when it is not deformed. In turn, Figure 7 also shows a decrease in the strain hardening index, which is in accordance with the results shown in Figure 9. The curve for $25^{\circ} \mathrm{C}$ shows a value for $\frac{d \sigma_{v}}{d \varepsilon_{v}}$ between 4000 and $1800 \mathrm{MPa}$, and the three stages $(\mathrm{A}, \mathrm{B}$, and $\mathrm{C}$ ) that correspond to a glide dislocation predominance, start of twinning, and decrease in twinning rate, respectively, are similar to those values reported by De Cooman et al. [22] for a 1 GPa TWIP steel.

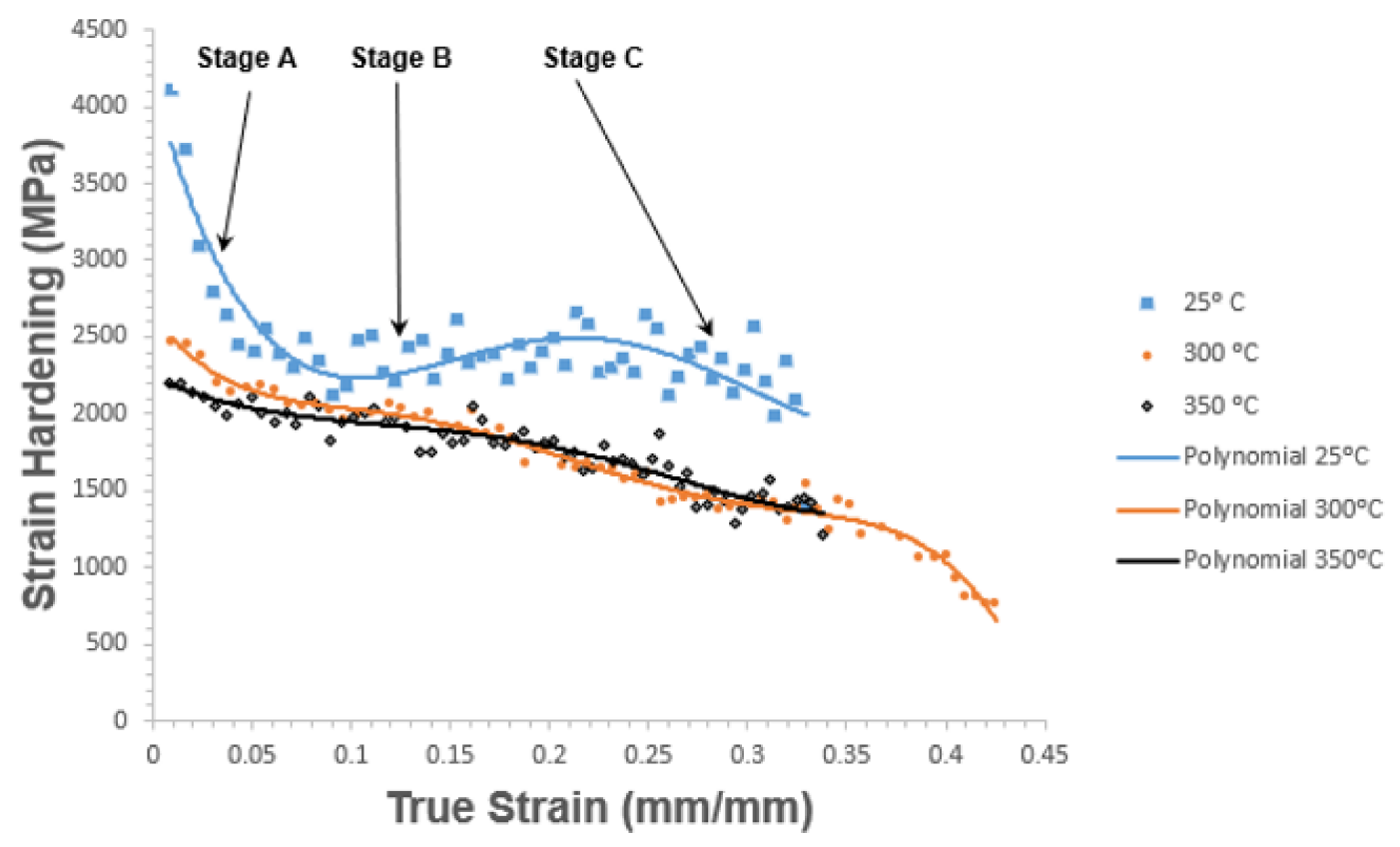

Figure 9. Strain hardening behavior at different temperatures.

\section{Conclusions}

High-temperature tensile tests were carried out in a Fe-22Mn-0.65C TWIP steel. The analysis of mechanical data combined with the microstructural characterization suggest the transition of the deformation mechanisms with temperature at $\sim 325^{\circ} \mathrm{C}$. While twinning is the most observed microstructural feature at low temperatures, dislocation slip is the most active one at high temperatures. The application of an Arrhenius-type relationship showed activation energies for yield stress 
comparable to twinning and dislocation slip at low and high temperatures, respectively. The transition in the failure mode of tensile test specimens, from nonlocalized at low temperatures to necking at high temperatures, suggests consistency with the transition in deformation mechanism previously suggested. The mechanical behavior described by means of strain hardening rate $\left(\frac{d \sigma_{v}}{d \varepsilon_{v}}\right)$ shows a good agreement with the microstructural features found at different temperatures (twinning vs dislocation slip), which in turn are consistent with global parameters analyzed such as strain hardening index (n) and area reduction. Also, it was confirmed that the behaviors of these kind of steels are strongly dependent on the SFE, being perhaps the most important parameter that determines the mechanical behavior of a TWIP steel. Finally, one of the most important aspects of the physical metallurgy of these steels is the twinning volume fraction at different temperatures. Determination of this parameter could give additional evidence about the relationship between twinning, SFE, and temperature.

Acknowledgments: The authors gratefully acknowledge the support of "Proyectos Basal USA 1555-Vridei 051714MG_MOV. Universidad Santiago de Chile", FONDECYT Grant 1140241, and DICYT USACH.

Author Contributions: Flavio De Barbieri: experiments, data analysis and discussion; Felipe Castro Cerda: thermodynamic analysis, discussion and part of the metallographic analysis; Juan Pérez-Ipiña: discussion and structure of the paper; Alfredo Artigas: tension tests and experimental support; Alberto Monsalve: discussion, planification of experiments and final redaction.

Conflicts of Interest: The authors declare no conflicts of interest.

\section{References}

1. Frommeyer, G.; Brüx, U.; Neumann, P. Supra-Ductile and High-Strength Manganese-TRIP/TWIP Steels for High Energy Absorption Purposes. ISIJ Int. 2003, 43, 438-446. [CrossRef]

2. Bouaziz, O.; Allain, S.; Scott, C.P.; Cugy, P.; Barbier, D. High manganese austenitic twinning induced plasticity steels: A review of the microstructure properties relationships. Curr. Opin. Solid State Mater. Sci. 2011, 15, 141-168. [CrossRef]

3. Grässel, O.; Krüger, L.; Frommeyer, G.; Meyer, L.W. High strength Fe-Mn-(Al, Si) TRIP/TWIP steels development-Properties-Application. Int. J. Plast. 2000, 16, 1391-1409. [CrossRef]

4. De Cooman, B.C.; Estrin, Y.; Kim, S.K. Twinning-induced plasticity (TWIP) steels. Acta Mater. 2018, 142, 283-362. [CrossRef]

5. Mahajan, S.; Williams, D.F. Deformation Twinning in Metals and Alloys. Int. Metall. Rev. 1973, $18,43-61$.

6. Christian, J.W.; Mahajan, S. Deformation twinning. Prog. Mater. Sci. 1995, 39, 1-157. [CrossRef]

7. Jung, I.-C.; de Cooman, B.C. Temperature dependence of the flow stress of Fe-18Mn-0.6C-xAl twinning-induced plasticity steel. Acta Mater. 2013, 61, 6724-6735.

8. Lee, E.H.; Byun, T.S.; Hunn, J.D.; Yoo, M.H.; Farrell, K.; Mansur, L.K. On the origin of deformation microstructures in austenitic stainless steel: Part I-Microstructures. Acta Mater. 2001, 49, 3269-3276. [CrossRef]

9. Lee, E.H.; Byun, T.S.; Hunn, J.D.; Yoo, M.H.; Farrell, K.; Mansur, L.K. On the origin of deformation microstructures in austenitic stainless steel: Part II-Mechanisms. Acta Mater. 2001, 49, 3277-3287. [CrossRef]

10. De Cooman, B.C.; Chen, L.; Kim, H.S.; Estrin, Y.; Kim, S.K.; Voswinckel, H. State-of-the-Science of High Manganese TWIP Steels for Automotive Applications. In Microstructure and Texture in Steels and Other Materials; Haldar, A., Suwas, S., Bhattacharjee, D., Eds.; Springer: Jamshedpur, India, 2009; pp. 165-182.

11. Rahman, K.M.; Jones, N.G.; Dye, D. Micromechanics of twinning in a TWIP steel. Mater. Sci. Eng. A 2015, 635, 133-142. [CrossRef]

12. Saleh, A.; Gazder, A. A re-evaluation of "The micromechanics of twinning in a TWIP steel". Mater. Sci. Eng. A 2016, 649, 184-189. [CrossRef]

13. Galindo-Nava, E.I.; Rivera-Díaz-del-Castillo, P.E.J. Understanding martensite and twin formation in austenitic steels: A model describing TRIP and TWIP effects. Acta Mater. 2017. [CrossRef]

14. Wong, S.L.; Madivala, M.; Prahl, U.; Roters, F.; Raabe, D. A crystal plasticity model for twinning- and transformation-induced plasticity. Acta Mater. 2016, 118, 140-151. [CrossRef]

15. Materials Analysis Using Diffraction (MAUD). Available online: http:/ / maud.radiographema.com (accessed on 22 May 2012). 
16. Dumay, A.; Chateau, J.-P.; Allain, S.; Migot, S.; Bouaziz, O. Influence of addition elements on the stacking-fault energy and mechanical properties of an austenitic Fe-Mn-C steel. Mater. Sci. Eng. A 2008, 483-484, 184-187. [CrossRef]

17. Curtze, S.; Kuokkala, V.-T. Dependence of tensile deformation behavior of TWIP steels on stacking fault energy, temperature and strain rate. Acta Mater. 2010, 58, 5129-5141. [CrossRef]

18. Olson, G.B.; Cohen, M. A general mechanism of martensitic nucleation: Part I. General concepts and the FCC $\rightarrow$ HCP transformation. Metall. Trans. A 1976, 7, 1897-1904.

19. Curtze, S.; Kuokkala, V.-T.; Oikari, A.; Talonen, J.; Hänninen, H. Thermodynamic modeling of the stacking fault energy of austenitic steels. Acta Mater. 2011, 59, 1068-1076. [CrossRef]

20. Monsalve, A.; de Barbieri, F.; Gómez, M.; Artigas, A.; Carvajal, L.; Sipos, K.; Bustos, O.; Pérez-Ipiña, J. Mechanical Behavior of a Twip Steel (Twinning Induced Plasticity). Matéria 2015, 20, 653-658. [CrossRef]

21. Dastur, Y.N.; Leslie, W.C. Mechanism of work hardening in Hadfield manganese steel. Metall. Trans. A 1981, 12, 749-759. [CrossRef]

22. De Cooman, B.C.; Kwon, O.; Chin, K.-G. State-of-the-knowledge on TWIP steel. Mater. Sci. Technol. 2012, 28, 513-527. [CrossRef]

(C) 2018 by the authors. Licensee MDPI, Basel, Switzerland. This article is an open access article distributed under the terms and conditions of the Creative Commons Attribution (CC BY) license (http://creativecommons.org/licenses/by/4.0/). 